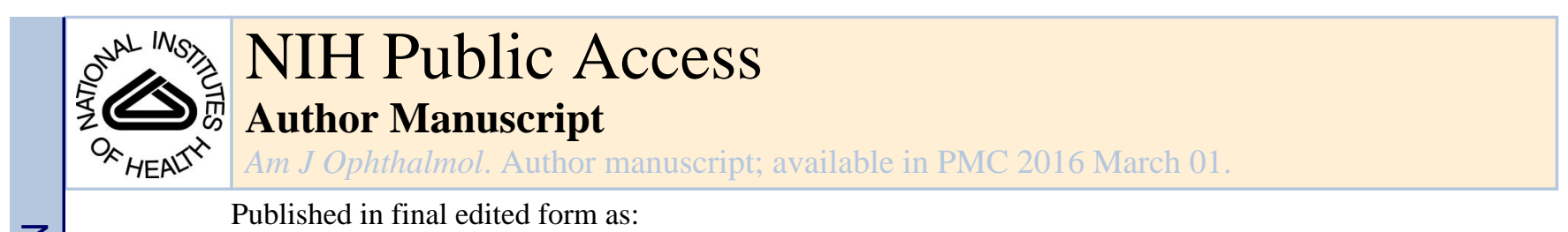

Published in final edited form as:

Am J Ophthalmol. 2015 March ; 159(3): 539-544.e2. doi:10.1016/j.ajo.2014.12.003.

\title{
Quality of Life in Adults with Strabismus
}

Melinda Y. Chang ${ }^{1,2}$, Federico G. Velez ${ }^{1,2}$, Joseph L. Demer ${ }^{1,2}$, Sherwin J. Isenberg ${ }^{1,2}$, Anne L. Coleman ${ }^{1,2}$, and Stacy L. Pineles ${ }^{1,2}$

${ }^{1}$ Stein Eye Institute, University of California, Los Angeles, California

${ }^{2}$ Department of Ophthalmology, University of California, Los Angeles, California

\section{Abstract}

Purpose-To assess relative quality of life in patients with strabismus.

Design-Retrospective cohort study

Methods-The 25-item National Eye Institute Visual Functioning Questionnaire (NEI VFQ-25) was performed in 42 strabismic adults over the age of 50 years at a single institution. Subscale scores were compared with those of patients with other ocular diseases, including diabetic retinopathy, age-related macular degeneration (AMD), glaucoma, cataract, cytomegalovirus (CMV) retinitis, and low vision.

Results-Median visual acuity was 20/20 (range 20/12.5 to 20/50), and 34 patients (81\%) reported diplopia. Strabismic patients performed the same or worse on nearly all vision-related subscales than did patients with diabetic retinopathy, age-related macular degeneration, glaucoma, cataract, and CMV retinitis. Additionally, strabismic patients reported significantly worse ocular pain than all comparison groups before any surgery was performed.

Conclusions-Strabismus impacts quality of life through both functional and psychosocial factors. Physicians treating strabismic patients should recognize these quality of life issues and address them accordingly.

\section{INTRODUCTION}

Strabismus affects approximately $4 \%$ of the adult population ${ }^{1}$ and can have functional effects. In addition to diplopia, patients may be troubled by the abnormal facial appearance of strabismus. ${ }^{2-8}$ Additionally, patients with strabismus are more likely to have mental health problems, ${ }^{9}$ including high rates of depressive symptoms and social phobia. ${ }^{10,11}$

\footnotetext{
(c) 2014 Elsevier Inc. All rights reserved.

Corresponding author: Stacy L. Pineles, M.D., Department of Ophthalmology, the Stein Eye Institute, 100 Stein Plaza, University of California, Los Angeles, Pineles@jsei.ucla.edu, Phone number: 310-267-1007, Fax: 310-825-0151.

Supplemental material available at AJO.com

Publisher's Disclaimer: This is a PDF file of an unedited manuscript that has been accepted for publication. As a service to our customers we are providing this early version of the manuscript. The manuscript will undergo copyediting, typesetting, and review of the resulting proof before it is published in its final citable form. Please note that during the production process errors may be discovered which could affect the content, and all legal disclaimers that apply to the journal pertain.
} 
Little is known about how quality of life in strabismic patients compares to that in patients with other ocular diseases. One study reported that patients who underwent surgery for incomitant strabismus reported greater improvement in quality of life using the Visual Function Questionnaire-14 than patients who had surgery for diabetic macular edema, comitant strabismus, glaucoma with cataract, and glaucoma alone. The improvement in quality of life for patients with incomitant strabismus who underwent surgery was similar to patients who had cataract surgery. ${ }^{12}$ However, to date there has been no comparison of quality of life in strabismus to other ocular diseases that includes both surgical and nonsurgical patients.

The 25-item National Eye Institute Visual Functioning Questionnaire (NEI VFQ-25) is a reliable and valid scale that captures the influence of vision on multiple dimensions of quality of life including emotional well-being and social functioning. ${ }^{13}{ }^{14}$ The NEI VFQ-25 subscale scores of patients with diabetic retinopathy, age-related macular degeneration (AMD), glaucoma, cataract, cytomegalovirus (CMV) retinitis, and low vision have been reported previously. ${ }^{14}$ By comparing the NEI VFQ-25 scores in strabismic patients to these patients, this study aimed to demonstrate the relative impact of strabismus on quality of life.

\section{METHODS}

This retrospective study was approved by the University of California, Los Angeles Institutional Review Board and conformed to the requirements of the US Health Insurance Portability and Accountability Act. Written informed consent was obtained from the participants. Strabismic patients were recruited during 2010 to 2012 from the clinics of 4 strabismologists (S.L.P., J.L.D., F.G.V., and S.J.I.) during preoperative visits. Only patients over the age of 50 were included in this study, to permit a closer comparison to the NEI VFQ-25 Field Test groups. ${ }^{14}$

Since these quality of life surveys were part of a larger study with pre-existing exclusion criteria, patients with any known history of treatment for amblyopia, dissociated vertical or dissociated horizontal deviation as the sole form of strabismus, pathologic nystagmus, or neurologic diseases were excluded.

\section{Demographic and clinical data}

The following demographic and clinical data were collected: age, sex, ethnicity, type of strabismus, other ocular diseases, and presence or absence of diplopia. Visual acuity and stereoacuity were measured as described below.

Participants underwent visual acuity examination using the Early Treatment Diabetic Retinopathy Study (ETDRS) protocol with their habitual refractive correction. ${ }^{15}$ If visual acuity was worse than 0.20 log-MAR in either eye, manifest refraction was performed and the study tests were performed with this refraction.

Binocular visual acuity was tested using the Precision Vision 3 meter ETDRS chart and the ETDRS protocol. ${ }^{15}$ The visual acuity score was calculated as the total number of correct letters plus 30 letters. The maximum score of 100 letters corresponded to a Snellen visual 
acuity of 20/10. Visual acuity was converted to Snellen acuity using the ETDRS chart to facilitate comparison with NEI VFQ-25 Field Test groups. ${ }^{14}$

Near stereoacuity was evaluated using the Titmus Near Stereo Test (Stereo Optical Co., Chicago, Il). Distance stereoacuity was measured using the Distance Randot Stereotest (Stereo Optical Co., Chicago, Il).

\section{NEI VFQ-25 scoring}

NEI VFQ-25 interviews were conducted by trained technicians. Using the NEI VFQ-25 scoring algorithm, ${ }^{16}$ the patients' answers were converted to a 100-point scale, with 100 being the optimum score and 0 being the worst score. The scores were averaged to generate 12 subscale scores: General Health, General Vision, Ocular Pain, Near Activities, Distance Activities, Vision-Specific Social Functioning, Vision-Specific Mental Health, VisionSpecific Role Difficulties, Vision-Specific Dependency, Driving, Color Vision, and Peripheral Vision. Means and standard deviations of the subscale scores for the patients with strabismus were calculated.

\section{Comparison of NEI VFQ-25 scores}

Comparisons were made to published NEI VFQ-25 subscale scores for diabetic retinopathy, age-related macular degeneration, glaucoma, cataract, CMV retinitis, and low vision. ${ }^{14}$ Differences were calculated using a two-sample t-test, with a p value of 0.05 or less considered significant. Since a total of 72 comparisons were performed, the Bonferroni correction was applied, and the corrected threshold for significance was determined to be 0.0007 .

\section{RESULTS}

Forty-two patients over the age of 50 with strabismus participated in the study. Demographic and clinical features of these patients are shown in Table 1. Mean age was 65 years old (range 52 to 90 years old). Twenty-two patients (54\%) were female. Median binocular visual acuity was 20/20 (range 20/12.5 to 20/50). Ethnicity was reported as white in 36 patients, Asian in three patients, and Hispanic in three patients.

Types of strabismus included 15 patients with esotropia, 8 patients with exotropia, 15 patients with hypertropia, and four patients with combined vertical and horizontal deviations. Diplopia was reported by 34 patients $(81 \%)$. Fifteen patients $(36 \%)$ had measurable stereoacuity at near, and 9 patients $(21 \%)$ had measurable stereoacuity at distance.

Table 2 compares age, sex, and binocular visual acuity between the strabismic patients and the comparison groups. Age was significantly different between the strabismic patients and all other groups, except glaucoma patients $(\mathrm{p}=0.29)$ and low vision patients $(\mathrm{p}=0.17)$. Patients with diabetic retinopathy and CMV retinitis were younger than strabismic patients, whereas patients with age-related macular degeneration and cataracts were older than strabismic patients. The sex distribution was not significantly different between strabismic patients and the other groups, except CMV retinitis, in which nearly all patients were male 
( $p<0.0001$ ). Median binocular visual acuity was $20 / 20$ in the strabismic patients, which was the same as CMV retinitis patients, and within three lines of the diabetic retinopathy, glaucoma, and cataract groups. Median binocular visual acuity was 20/63 in age-related macular degeneration patients, six lines worse than the strabismic patients.

The NEI VFQ-25 subscale scores for strabismic patients and comparison groups are shown in Table 3. Statistically significant differences between strabismic patients and other groups at a threshold of 0.0007 (calculated using the Bonferroni correction) are indicated by the shading of cells in the table. Cells shaded dark gray indicate subscale scores that were significantly better than strabismic patients, light gray cells denote subscale scores that were not significantly different from strabismic patients, and white cells indicate subscale scores that were significantly worse than strabismic patients. Supplemental Table 1 shows the same comparisons with the p-value for significance set to 0.05 . With the exception of the General Health subscale, nearly all subscale scores were significantly worse or not significantly different in strabismic patients compared to patients with diabetic retinopathy, age-related macular degeneration, glaucoma, cataract, and CMV retinitis. The subscale scores that were significantly better in strabismic patients were Driving and Color Vision compared to agerelated macular degeneration patients. Additionally, subscale scores were significantly better or not significantly different in patients with strabismus compared to low vision patients, except for the Ocular Pain subscale. Strabismic patients reported significantly worse ocular pain than patients in all other groups.

Nine strabismic patients also had other ocular disorders, including cataract $(\mathrm{n}=3)$, glaucoma $(n=1)$, age-related macular degeneration $(n=1)$, dry eye $(n=1)$, high myopia $(n=1)$, retinal detachment $(\mathrm{n}=1)$, and blepharoptosis $(\mathrm{n}=1)$. A separate analysis excluding strabismic patients with these confounding ocular diseases found no change in the direction of difference between subscale scores of strabismic patients and the comparison groups.

\section{DISCUSSION}

We present the first report, to our knowledge, comparing quality of life in strabismic patients to patients with other ocular diseases using a standardized scale assessing visual functioning and including both surgical and non-surgical patients. We found that, with the exception of patients with low vision, patients with strabismus performed the same or worse on nearly all vision-related subscales. Additionally, we found that strabismic patients reported significantly worse ocular pain than patients with all other ocular diseases studied.

Decreased quality of life in strabismic patients compared to patients with other ocular diseases may be related to both functional and psychosocial factors. In our study, 34 (81\%) of patients reported diplopia. Diplopia has been associated with decreased quality of life using both the NEI VFQ-25 and Adult Strabismus-20 (AS-20) scales. ${ }^{17,} 18$ Other detrimental effects of strabismus on vision may include lack of stereopsis, as well as decreased binocular summation. Binocular summation is characterized by an improvement in certain aspects of vision, such as low-contrast vision, when viewing under binocular rather than monocular conditions. We have shown that strabismic patients have subnormal binocular summation, and even binocular inhibition (worse visual function with binocular compared to monocular 
viewing) and this is associated with diminished quality of life. ${ }^{19,20}$ Our findings suggest that diplopia and other factors affecting vision in strabismic patients may have a greater impact on visual functioning than factors affecting vision in the other ocular diseases studied.

Psychosocial factors may also contribute to worse quality of life in strabismic patients, since appearance, as well as vision, may be affected. Quality of life in strabismic patients has been shown to be correlated with scores on the Derriford Appearance Scale, which evaluates the effect of appearance on psychosocial functioning. Strabismic patients who reported more appearance-related distress were also found to have worse quality of life. ${ }^{21}$ Others have found that strabismus negatively affects self-image, job prospects, relationships, education, and sports. ${ }^{2-8}$ Additionally, young adults with a history of childhood strabismus have a higher rate of mental health problems $(41.3 \%)$ than controls $(30.7 \%) .{ }^{9}$ Unoperated strabismic patients have a high rate of social phobia at $54.8 \% ;{ }^{11}$ poor quality of life in strabismic patients has been associated with increased depressive symptoms. ${ }^{10}$

Interestingly, we found that ocular pain was significantly worse in strabismic patients compared to all other groups. Patients were assessed prior to surgical intervention, so increased ocular pain was not related to surgery. Other known causes of ocular pain, such as dry eye syndrome, inflammation, and acutely elevated intraocular pressure were not found in the strabismic patients, except one patient who was diagnosed with dry eyes. One possible explanation for the increased ocular pain in strabismic patients is that they experienced asthenopia related to their eye misalignment. The role of asthenopia on quality of life in strabismic patients has been minimally studied in the literature. However, Beauchamp et al reported that physician ratings of asthenopia were correlated with patient-reported willingness to trade life expectancy to be rid of strabismus. ${ }^{22}$ Depression is associated with more intense pain symptoms, ${ }^{23,24}$ and it is possible that the strabismic patients reported more ocular pain due to the higher prevalence of depressive symptoms in this group. Our results suggest that ocular pain may play a more important role in quality of life in strabismic patients than previously thought.

We also found that strabismic patients reported significantly worse vision-specific mental health and role difficulties compared to patients with glaucoma, cataracts, and CMV retinitis. This highlights the importance of the detrimental psychosocial effects of strabismus, which may be related to the asymmetric appearance caused by eye misalignment. ${ }^{2-10}$ Additionally, on the peripheral vision subscale, strabismic patients performed significantly worse than patients with cataracts, and not statistically different from patients with glaucoma. This may be related to the restriction in binocular visual field caused by some forms of strabismus. ${ }^{25}$

Because we were unable to obtain the raw data for the comparison groups, we were unable to control for the effect of visual acuity on quality of life. However, given that the median visual acuity of our strabismic patients was 20/20, the same or better than that of the other groups, we would expect that any effect of visual acuity on quality of life would favor better scores for the strabismic patients. Since strabismic patients performed the same or worse on nearly all comparisons (except for low vision patients), it follows that if the effect of visual 
acuity were eliminated, the direction of the observed difference would not change; in fact, the magnitude of the difference may increase. With the exception of low vision patients, patients with age-related macular degeneration had the worst median visual acuity and were the only patients who performed worse than strabismic patients on a subscale other than General Health. One study found that a two-line change in visual acuity translated to a 2.4 to 7.0 point change in NEI VFQ-25 subscale scores. ${ }^{26}$ Median visual acuity in the age-related macular degeneration group was six lines worse than that of the strabismus group. The subscale scores that were significantly worse in age-related macular degeneration patients compared to strabismic patients were within the range that would be expected based on the difference in visual acuity. Thus, it is possible that these subscale scores were worse in the age-related macular degeneration group due to worse visual acuity.

Other factors that may affect visual functioning and confound our comparison of quality of life scores include age, sex, race, and other ocular diseases. Sex distribution was not significantly different between our strabismic patients and the other groups, except for patients with CMV retinitis, who were nearly all male. Age was significantly different between our strabismic patients and all other groups, except glaucoma and low vision patients. The effect of age on quality of life is unclear. In strabismic patients, some reports have found worse quality of life in younger patients, ${ }^{10}$ others have reported worse scores in older patients, ${ }^{27}$ and still others have found no effect of age on quality of life. ${ }^{28}$ The NEI VFQ-25 field test sample included 63\% whites and 29\% African Americans, whereas our study group of strabismic patients included $86 \%$ whites, and no African Americans. Race and ethnicity have been shown to affect self-reported quality of life in multiple diseases, with minorities typically reporting worse quality of life. ${ }^{29-32}$ As our strabismic patients were more likely to be white but also reported worse quality of life, we would not expect the difference in racial composition to significantly alter our findings, although we recognize that the relationship between race and self-reported quality of life is complex and multifactorial. Finally, few of our strabismic patients had potentially confounding ocular disorders, with cataracts in only three patients, and age-related macular degeneration, retinal detachment, glaucoma, dry eyes, high myopia, and blepharoptosis in only one patient each (Table 1). When the nine patients with other ocular disorders were excluded from analysis, there was no change in the direction of difference when comparing the subscale scores of strabismic patients to patients with other ocular diseases.

These findings underscore the importance of attention to quality of life issues in patients with strabismus, as this disease may have functional and psychosocial implications not traditionally addressed by a typical ophthalmologic clinic visit.

\section{Supplementary Material}

Refer to Web version on PubMed Central for supplementary material.

\section{Acknowledgments}

\section{ACKNOWLEDGMENTS AND DISCLOSURES}

a. Funding/Support: 
a. National Institutes of Health/National Eye Institute K23EY021762 (SLP)

b. Knights Templar Eye Foundation (SLP)

c. Oppenheimer Family Foundation (SLP)

b. Financial Disclosures:

a. Melinda Chang: none

b. Federico Velez: none

c. Joseph Demer:

i. Research grant reviewer for National Eye Institute, Knights Templar Eye Foundation

ii. National Eye Institute EY08313 Research Grant

iii. Honoraria and travel reimbursements for visiting professorships and lectures

iv. Small royalties for book chapters

d. Sherwin Isenberg: Consultant for Foresight Biotherapeutics

e. Anne Coleman: none

f. Stacy Pineles: National Institutes of Health/National Eye Institute K23EY021762 grant

c. Contributions of Authors:
a. Design of the study (MC, AC, SP)
b. Conduct of the study (MC, SP)
c. Data collection (FV, JD, SI, SP)
d. Data management (MC, SP)
e. Analysis (MC, SP)
f. Interpretation of the data (MC, SP)
g. Preparation and review of manuscript (MC, FV, JD, SI, AC, SP)

\section{References}

1. Coats DK, Stager DR Sr, Beauchamp GR, et al. Reasons for delay of surgical intervention in adult strabismus. Arch Ophthalmol. 2005; 123(4):497-9. [PubMed: 15824223]

2. Menon V, Saha J, Tandon R, Mehta M, Khokhar S. Study of the psychosocial aspects of strabismus. J Pediatr Ophthalmol Strabismus. 2002; 39(4):203-8. [PubMed: 12148552]

3. Satterfield D, Keltner JL, Morrison TL. Psychosocial aspects of strabismus study. Arch Ophthalmol. 1993; 111(8):1100-5. [PubMed: 8166786]

4. Burke JP, Leach CM, Davis H. Psychosocial implications of strabismus surgery in adults. J Pediatr Ophthalmol Strabismus. 1997; 34(3):159-64. [PubMed: 9168420]

5. Hatt SR, Leske DA, Kirgis PA, Bradley EA, Holmes JM. The effects of strabismus on quality of life in adults. Am J Ophthalmol. 2007; 144(5):643-7. [PubMed: 17707329]

6. Nelson BA, Gunton KB, Lasker JN, Nelson LB, Drohan LA. The psychosocial aspects of strabismus in teenagers and adults and the impact of surgical correction. J AAPOS. 2008; 12(1):7276. e1. [PubMed: 18314071]

7. Jackson S, Harrad RA, Morris M, Rumsey N. The psychosocial benefits of corrective surgery for adults with strabismus. Br J Ophthalmol. 2006; 90(7):883-8. [PubMed: 16782950]

8. Durnian JM, Noonan CP, Marsh IB. The psychosocial effects of adult strabismus: a review. Br J Ophthalmol. 2011; 95(4):450-3. [PubMed: 20852320]

9. Mohney BG, McKenzie JA, Capo JA, Nusz KJ, Mrazek D, Diehl NN. Mental illness in young adults who had strabismus as children. Pediatrics. 2008; 122(5):1033-8. [PubMed: 18977984]

10. Hatt SR, Leske DA, Liebermann L, Philbrick KL, Holmes JM. Depressive Symptoms Associated with Poor Health-Related Quality of Life in Adults with Strabismus. Ophthalmology. 2014; 121(10):2070-1. [PubMed: 24908202] 
11. Alpak G, Coskun E, Erbagci I, et al. Effects of corrective surgery on social phobia, psychological distress, disease-related disability and quality of life in adult strabismus patients. Br J Ophthalmol. 2014; 98(7):876-9. [PubMed: 24627249]

12. Kishimoto F, Ohtsuki H. Comparison of VF-14 scores among different ophthalmic surgical interventions. Acta Med Okayama. 2012; 66(2):101-10. [PubMed: 22525468]

13. Mangione CM, Lee PP, Pitts J, Gutierrez P, Berry S, Hays RD. Psychometric properties of the National Eye Institute Visual Function Questionnaire (NEI-VFQ). NEI-VFQ Field Test Investigators. Arch Ophthalmol. 1998; 116(11):1496-504. [PubMed: 9823352]

14. Mangione CM, Lee PP, Gutierrez PR, et al. Development of the 25-item National Eye Institute Visual Function Questionnaire. Arch Ophthalmol. 2001; 119(7):1050-8. [PubMed: 11448327]

15. Early Treatment Diabetic Retinopathy Study design and baseline patient characteristics. ETDRS report number 7. Ophthalmology. 1991; 98(5 Suppl):741-56. [PubMed: 2062510]

16. Mangione CM. The National Eye Institute 25-Item Visual Function Questionnaire-25 Scoring Algorithm. 2000

17. Wu-Chen WY, Christoff A, Subramanian PS, Eggenberger ER. Diplopia and quality of life. Ophthalmology. 2011; 118(7):1481-1481. e2. [PubMed: 21724046]

18. McBain HB, Au CK, Hancox J, et al. The impact of strabismus on quality of life in adults with and without diplopia: a systematic review. Surv Ophthalmol. 2014; 59(2):185-91. [PubMed: 24359806]

19. Pineles SL, Velez FG, Isenberg SJ, et al. Functional burden of strabismus: decreased binocular summation and binocular inhibition. JAMA Ophthalmol. 2013; 131(11):1413-9. [PubMed: 24052160]

20. Tandon AVF, Isenberg SJ, Demer JL, Pineles SL. Binocular inhibition in strabismic patients is associated with diminished quality of life. J AAPOS. In press.

21. Durnian JM, Owen ME, Marsh IB. The psychosocial aspects of strabismus: correlation between the AS-20 and DAS59 quality-of-life questionnaires. J AAPOS. 2009; 13(5):477-80. [PubMed: 19840727]

22. Beauchamp GR, Felius J, Stager DR, Beauchamp CL. The utility of strabismus in adults. Trans Am Ophthalmol Soc. 2005; 103:164-71. discussion 171-2. [PubMed: 17057800]

23. Berna C, Leknes S, Holmes EA, Edwards RR, Goodwin GM, Tracey I. Induction of depressed mood disrupts emotion regulation neurocircuitry and enhances pain unpleasantness. Biol Psychiatry. 2010; 67(11):1083-90. [PubMed: 20303069]

24. Hartman JM, Berger A, Baker K, et al. Quality of life and pain in premenopausal women with major depressive disorder: the POWER Study. Health Qual Life Outcomes. 2006; 4:2. [PubMed: 16420706]

25. Pratt-Johnson JA, MacDonald AL. Binocular visual field in strabismus. Can J Ophthalmol. 1976; 11(1):37-41. [PubMed: 1247937]

26. Submacular Surgery Trials Research G. Evaluation of minimum clinically meaningful changes in scores on the National Eye Institute Visual Function Questionnaire (NEI-VFQ) SST Report Number 19. Ophthalmic Epidemiol. 2007; 14(4):205-15. [PubMed: 17896299]

27. McBain HB, MacKenzie KA, Au C, et al. Factors associated with quality of life and mood in adults with strabismus. Br J Ophthalmol. 2014; 98(4):550-5. [PubMed: 24390164]

28. Durnian JM, Owen ME, Baddon AC, Noonan CP, Marsh IB. The psychosocial effects of strabismus: effect of patient demographics on the AS-20 score. J AAPOS. 2010; 14(6):469-71. [PubMed: 21168068]

29. Unruh M, Miskulin D, Yan G, et al. Racial differences in health-related quality of life among hemodialysis patients. Kidney Int. 2004; 65(4):1482-91. [PubMed: 15086492]

30. Quittner AL, Schechter MS, Rasouliyan L, Haselkorn T, Pasta DJ, Wagener JS. Impact of socioeconomic status, race, and ethnicity on quality of life in patients with cystic fibrosis in the United States. Chest. 2010; 137(3):642-50. [PubMed: 19820076]

31. Kovac SH, Mikuls TR, Mudano A, Saag KG. Health-related quality of life among self-reported arthritis sufferers: effects of race/ethnicity and residence. Qual Life Res. 2006; 15(3):451-60. [PubMed: 16547784] 
32. Spiers AWG. The Effects of Ethnicity and Leisure Satisfaction on Happiness, Peacefulness, and Quality of Life. Leisure Sciences. 2008; 31(1):84-99.

\section{Biography}

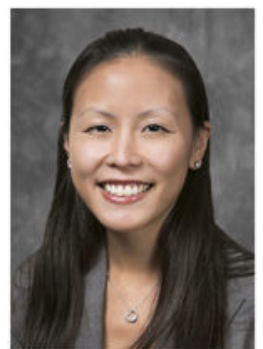

Melinda Y. Chang, MD, received her medical degree from Washington University in St. Louis, and is currently a senior resident at the Stein Eye Institute in Los Angeles, CA. She plans to complete a dual fellowship in pediatric ophthalmology and neuro-ophthalmology. Her research interests include complicated strabismus and pediatric neuro-ophthalmologic disorders. 
Table 1

Demographic and clinical characteristics of 42 patients with strabismus who participated in the Quality of Life in Adults with Strabismus study

\begin{tabular}{|c|c|c|}
\hline Mean age in years (range) & & $65(52$ to 90$)$ \\
\hline Female $(\%)$ & & $22(54 \%)$ \\
\hline Median binocular visual acuity (range) & & $20 / 20(20 / 12.5-20 / 50)$ \\
\hline \multirow[t]{3}{*}{ Ethnicity } & White & 36 \\
\hline & Asian & 3 \\
\hline & Hispanic or Latino & 3 \\
\hline \multirow[t]{4}{*}{ Type of strabismus } & Esotropia & 15 \\
\hline & Exotropia & 8 \\
\hline & Hypertropia & 15 \\
\hline & Combined vertical and horizontal strabismus & 4 \\
\hline \multirow[t]{7}{*}{ Other ocular disease } & Cataract & 3 \\
\hline & Glaucoma & 1 \\
\hline & AMD & 1 \\
\hline & Dry eyes & 1 \\
\hline & High myopia & 1 \\
\hline & Retinal detachment & 1 \\
\hline & Blepharoptosis & 1 \\
\hline Number of patients with measurable near stereoacuity (\%) & & $15(36 \%)$ \\
\hline Number of patients with measurable distance stereoacuity (\%) & & $9(21 \%)$ \\
\hline Diplopia (\%) & & $34(81 \%)$ \\
\hline
\end{tabular}

$\mathrm{ET}=$ esotropia; $\mathrm{XT}=$ exotropia; $\mathrm{AMD}=$ age-related macular degeneration 


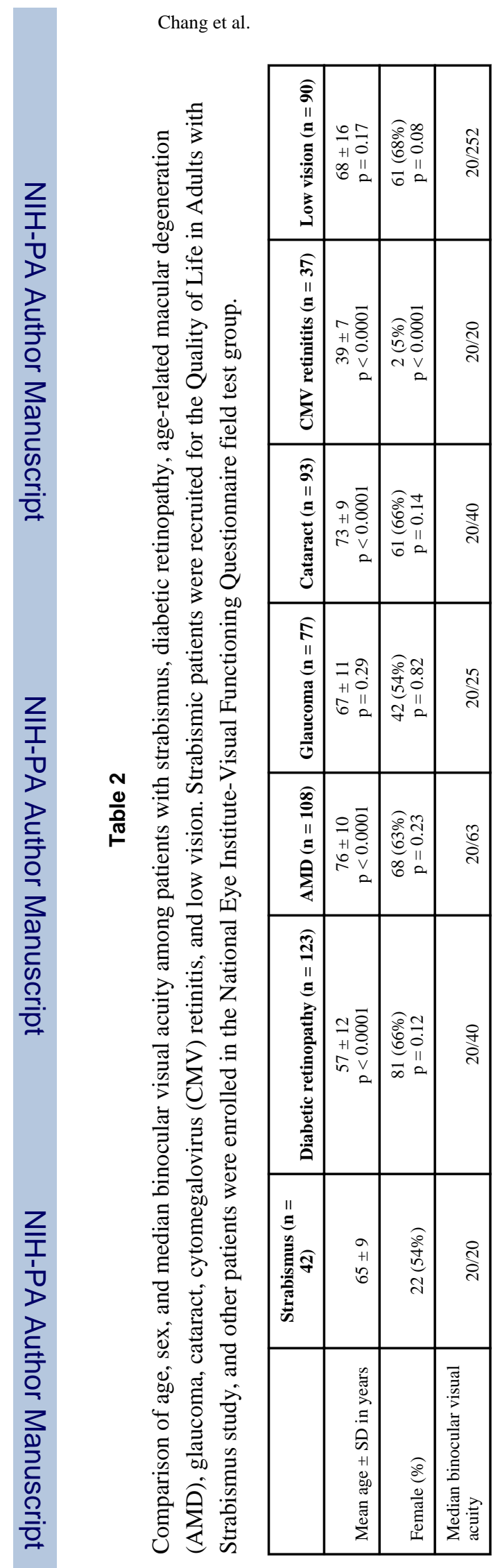

Page 11

\begin{tabular}{|c|c|c|c|}
\hline 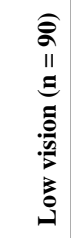 & $\begin{array}{ccc} & \\
& & \\
0 & = \\
+1 & 0 \\
0 & 11 \\
0 & 11 & 0\end{array}$ & 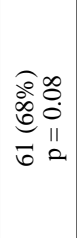 & \\
\hline 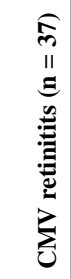 & $\begin{array}{rl}r & \overline{8} \\
+1 & 0 \\
\text { r) } & 0 \\
2 & \\
2\end{array}$ & 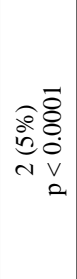 & \\
\hline 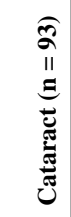 & 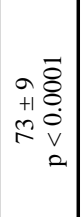 & 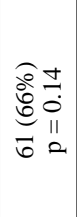 & \\
\hline 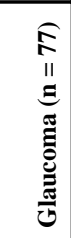 & $\begin{array}{ll}= & 0 \\
0 & \text { 1 } \\
+1 & 11 \\
5 & 11 \\
& 2\end{array} \mid$ & 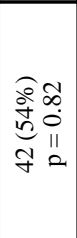 & \\
\hline 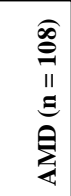 & 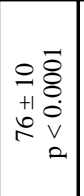 & 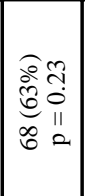 & \\
\hline 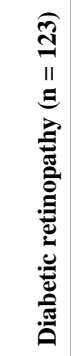 & 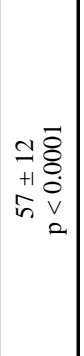 & 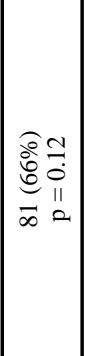 & \\
\hline 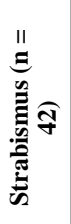 & $\begin{array}{l}a \\
+1 \\
b\end{array}$ & 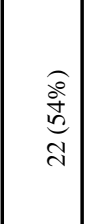 & \\
\hline & 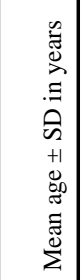 & 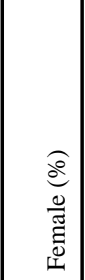 & 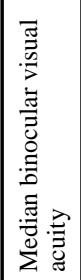 \\
\hline
\end{tabular}

Am J Ophthalmol. Author manuscript; available in PMC 2016 March 01. 


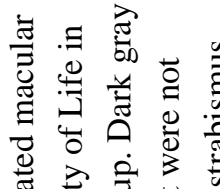

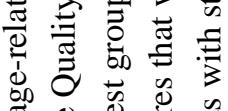

क्ष

خ吉吾

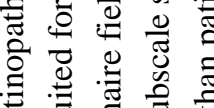

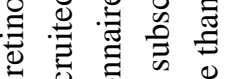

.己

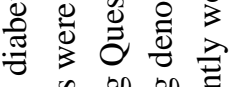

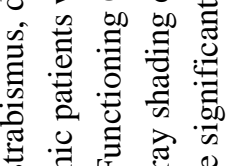

क

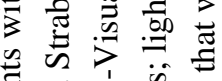

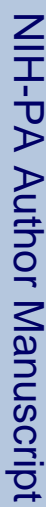

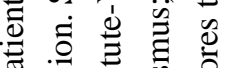

Z $\quad$ 产

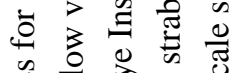

๓

๘

范

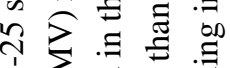

¿

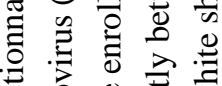

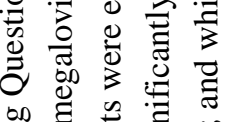

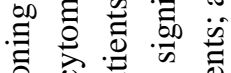

o

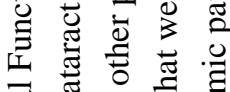

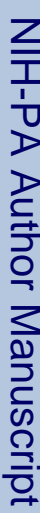

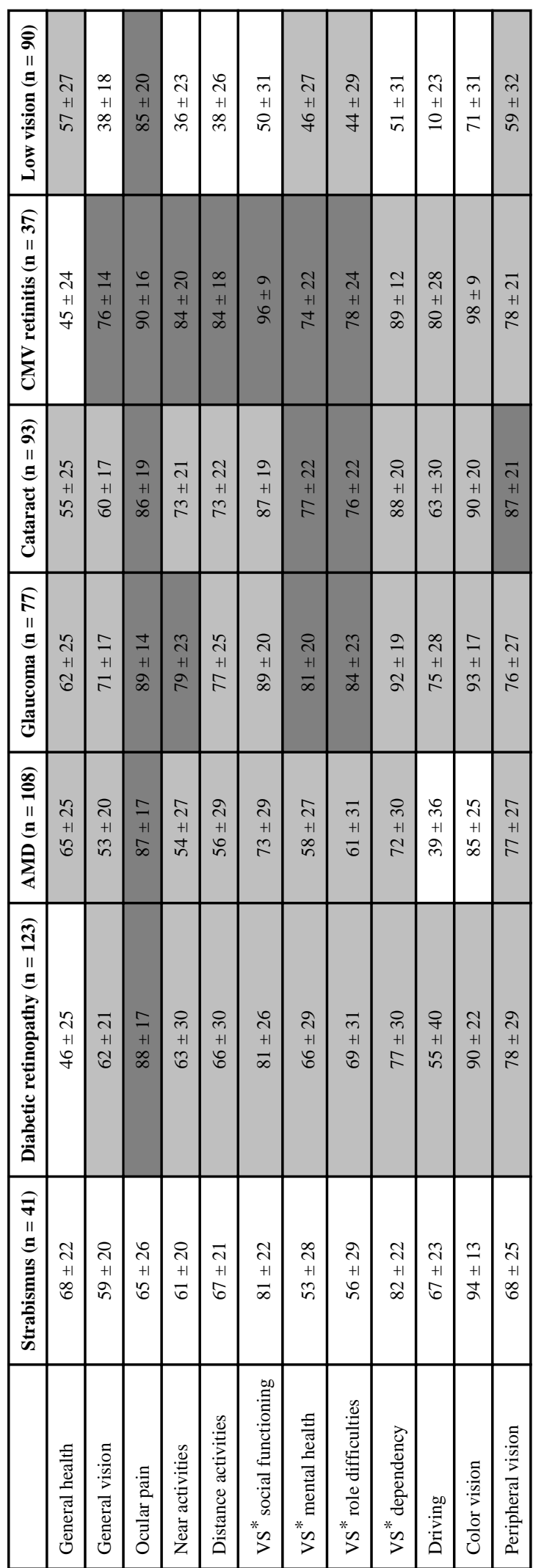

范

¿ ठ

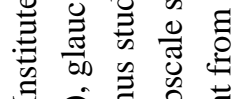

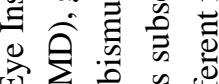

凷芯氙

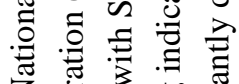

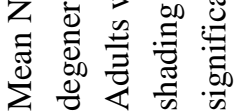

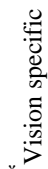

